\title{
Double deletion of the active zone proteins CAST/ELKS in the mouse forebrain causes high mortality of newborn pups
}

\author{
Akari Hagiwara, Shun Hamada, Yamato Hida and Toshihisa Ohtsuka*
}

\begin{abstract}
Presynaptic active zone cytomatrix proteins are essential elements of neurotransmitter release machinery that govern neural transmission. Among active zone proteins, cytomatrix at the active zone-associated structural protein (CAST) is known to regulate active zone size in retinal photoreceptors and neurotransmitter release by recruiting $\mathrm{Ca}^{2+}$ channels at various synapses. However, the role of ELKS - a protein from the same family as CAST_-and the synergistic roles of CAST/ELKS have not been thoroughly investigated, particularly with regard to mouse behavior. Here, we generated ELKS conditional KO in mouse forebrain synapses by crossing ELKS flox mice with a CaMKII promoter-induced Cre line. Results showed that CAST is dominant at these synapses and that ELKS can support CAST function, but is less effective in the ELKS single KO. Pups of CAST/ELKS double KO in the forebrain were born in Mendelian rations but resulted in eventual death right after the birth. Anatomically, the forebrain neuronal compositions of CAST KO and CAST/ELKS double KO mice were indistinguishable, and the sensory neural network from whiskers on the face was identified as barrelette-like patches in the spinal trigeminal nucleus. Therefore, depletion of CAST and ELKS disrupts neurotransmission from sensory to motor networks, which can lead to deficits in exploration and failure to suckle.
\end{abstract}

Keywords: Presynapse, Active zone, CAST, CaMKII Cre, CAZ proteins, Neurotransmitter release

\section{Maintext}

Sensory neural networks in the brain pass on information to other systems where it is processed and can then influence behavior. These networks are sustained by numerous excitatory and inhibitory synapses, each of which has pre- and post-synaptic sites. At the presynaptic active zone (AZ), neurotransmitter-containing synaptic vesicles dock close to voltage-gated $\mathrm{Ca}^{2+}$ channels and are made ready to fuse with the plasma membrane in a $\mathrm{Ca}^{2+}$-dependent manner. To organize the framework of neurotransmitter release, cytomatrix at the AZ (CAZ) proteins, including Munc13, RIM, Bassoon, CAST (also named ELKS2 $\alpha$ or ERC2), and ELKS (ELKS1 $\alpha$, CAST2, ERC1) perform a variety of roles such as formation and maintenance of synapses, tethering and docking synaptic vesicles at AZ-release sites, and recruitment of $\mathrm{Ca}^{2+}$ channels to the AZ [1-3]. As well as the deletion mutant

\footnotetext{
* Correspondence: tohtsuka@yamanashi.ac.jp

Department of Biochemistry, Faculty of Medicine, University of Yamanashi, 1110 Shimokato, Chuo, Yamanashi 409-3898, Japan
}

of each CAZ protein indicated their roles, organization of release site was complemented by differing CAZ proteins, as revealed by combinatorial deletion of proteins, such as ELKS (CAST/ELKS) and RIM, or RIM and RIM-BP, which resulted in a large reduction of docked vesicles and presynaptic dense projections, respectively $[4,5]$. In previous reports of the retinal photoreceptor-ribbon synapse, we have shown that CAST functions in AZ formation and the processing of neurotransmission [6]. Intriguingly, although the CAST-family protein ELKS complemented CAST's functional role with regard to neurotransmitter release, the size of the AZ in CAST/ELKS double KO (dKO) mice was comparable to that of CAST-only KO [7]. The roles of CAST and ELKS in recruiting $\mathrm{Ca}^{2+}$ channels to the release site were confirmed at other synapses, including the calyx of Held [8-10]. As a matter of course, the role of CAST in neurotransmission was investigated at the CAST KO hippocampal synapses [11, 12], in which the presynaptic release was increased at excitatory and inhibitory synapses, while the density of synapse and the AZ

(c) The Author(s). 2020 Open Access This article is distributed under the terms of the Creative Commons Attribution 4.0 International License (http://creativecommons.org/licenses/by/4.0/), which permits unrestricted use, distribution, and 
size was not altered. Analysis of CAST/ELKS dKO in hippocampal primary culture neurons indicated that unlike the RIM binding $\mathrm{C}$-terminal region, the $\mathrm{N}$-terminal region is essential for regulating the readily releasable pool of neurotransmitters [13].

However, the function of CAST/ELKS-related synaptic modulation with regard to behavior has not been well described. To determine any roles of CAST/ELKS on learning, memory and cognition at the cortex and/or hippocampus, we generated CAST KO and ELKS conditional $\mathrm{KO}(\mathrm{cKO})$ in the forebrain by crossing CaMKIICre mice [14]. As expected, behavior and synaptic connections in the hippocampus were not affected by the ELKS cKO in the forebrain. However, the CAST/ELKS $\mathrm{dKO}$ pups surprisingly died right after the birth. Further examination showed that this was despite an intact sensory network system for facial whiskers. Therefore, CAST/ELKS-responsible neurotransmission in the forebrain neural network is essential for newborn mice to acquire normal exploratory or suckling behavior.

\section{Results and discussion}

\section{Generation of ELKS CKO at the forebrain}

To understand the roles of ELKS in forebrain neural networks within the cortex and hippocampus, ELKS flox mice were crossed with Cre knockin mice in which Cre expression was regulated by the CaMKII promoter $[7,9,14]$. Both male and female ELKS cKO mice $\left(\mathrm{ELKS}^{\text {flox/flox}}\right.$; CaMKII $\mathrm{Cre}^{+/-}$) were viable and fertile, and they exhibited no gross developmental abnormalities, including body weight (Table 1). Weight of the forebrain in these mice was slightly but significantly smaller compared with controls (ELKS ${ }^{\text {flox/flox }}$; CaMKII $\mathrm{Cre}^{-1-}$ ), while that of the cerebellum did not differ (Fig. 1a). Cre recombinase targets exon 11 of ELKS and causes a frame shift in exons 12 and 13 [7, 9]. ELKS expression was confirmed by immunoblotting with antiELKS antibody raised against amino acid 121-165 located in the first coding exon (exon3), and testing indicated depletion of ELKS in the forebrain of $\mathrm{Cre}^{+}$mice (Fig. 1b). In previous reports, ELKS expression was compensatory enhanced in the forebrain, calyx of Held, and retina of CAST KO mice $[9,12]$. Similarly, CAST has been shown to be upregulated in ELKS cKO retinas [7]. In the current study, extensive ELKS depletion in the forebrain did not significantly affect CAST expression, presumably because CAST is dominant at the

Table 1 Body weight of control and ELKS CKO

\begin{tabular}{lll}
\hline & ELKS flox; Cre - (Cont) & ELKS flox; Cre + (ELKS cKO) \\
\hline Male & $24.5 \mathrm{~g} \pm 0.74(n=4)$ & $22.7 \mathrm{~g} \pm 0.71(n=7)$ \\
Female & $20.0 \mathrm{~g} \pm 0.50(n=5)$ & $20.0 \mathrm{~g} \pm 0.69(n=5)$
\end{tabular}

Values are means \pm SEM. Body weights of mice aged 9-12 weeks were averaged from the sample sizes $(n)$ majority of forebrain synapses-an assumption supported by CAST and ELKS mRNA expression (Allen Brain Atlas). We explored the functional relevance of ELKS in the forebrain by assessing behavior in a novel open field. The distance traveled, and resting time was indistinguishable between control and ELKS cKO mice (Fig. 1c-d, Table 2). Additionally, both control and ELKS cKO mice spent more time traveling along the peripheral zone (Outer) than within the center zone (Inner) (Fig. 1d, Table 2). Immunohistochemistry of the hippocampus confirmed the expression of Cre, especially in the granule cells of the dentate gyrus, following the depletion of ELKS in the CA1 and CA3 regions (Fig. 1e-g). In contrast, ELKS expression was not altered in the cerebellum, where CaMKII promoterinduced Cre was not detected by immunoblotting or immunohistochemistry (Fig. 1b, h). Furthermore, we used electron microscopy to investigate the ultrastructure of synapses in the CA1, which included mostly Schaffer-collateral to pyramidal neuron spines. Neither the density of excitatory synapses nor the size of the preterminal or the AZ significantly differed between ELKS cKO and controls (Fig. 1i-j, Table 3). Similar to a previous report of CAST KO [12], ELKS depletion had little effect on the anatomy of hippocampal synapses.

\section{Generation of CAST KO; ELKS CKO in the forebrain led to high mortality of new born pups}

Separate CAST and ELKS deletion in forebrain synapses showed that CAST predominantly works in neurotransmitter release $[11,12]$. However, because ELKS expression was upregulated in CAST KO [12], and presynaptic machinery proteins can complement each other's roles $[4,5]$, here we generated CAST/ELKS dKO mice by crossing ELKS flox with CaMKII $\mathrm{Cre}^{+/-}$mice with the CAST KO mice. From the CAST KO; ELKS ${ }^{\text {flox/flox; }}$ CaMKII $\mathrm{Cre}^{-/-}$with CAST KO; $\mathrm{ELKS}^{\text {flox/-}}$; CaMKII $\mathrm{Cre}^{+/-}$breeding pairs, genotype distribution of offspring was as follows: CAST KO; ELKS ${ }^{\text {flox/flox}}$; CaMKII $\mathrm{Cre}^{-/-}$

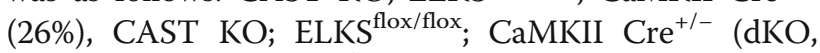
21\%), CAST KO; ELKS ${ }^{\text {flox/-}}$; CaMKII $\mathrm{Cre}^{-/-}$(33\%), and CAST KO; ELKS ${ }^{\text {flox/-}}$; CaMKII Cre Cre $^{+/-}$(19\%), corresponding to the expected Mendelian inheritance (Fig. 2a). Body weight of newborn pups did not significantly differ between CAST KO and dKO mice (Fig. 2b). Furthermore, depletion of CAST and ELKS was confirmed by immunoblotting (Fig. 2c). Although the offspring were in accordance with Mendelian law, we found that the $\mathrm{dKO}$ mice frequently died immediately after birth, and no dKO pup could survive more than one day (Fig. 2d). The pups were all reddish and appeared normal, suggesting functional cardiovascular and respiratory systems (Fig. 2e). However, unlike the other genotypes, the $\mathrm{dKO}$ pups had no milk in their stomachs. These results 


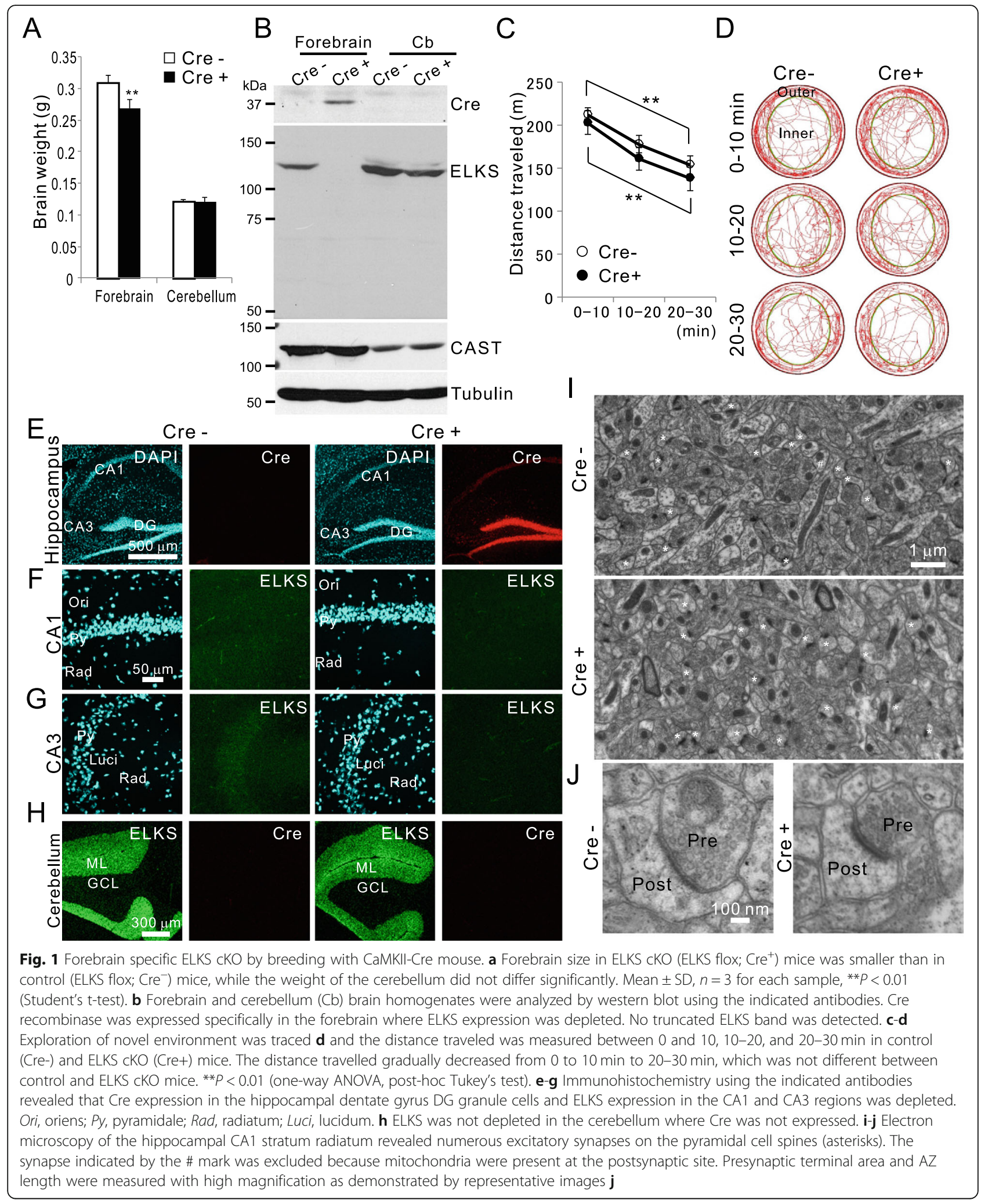

suggest that the CAST/ELKS dKO in the forebrain caused a defect in exploring and/or suckling behavior. Sensory signals for temperature, touch, and pain from the ipsilateral portion of a face pass through the spinal trigeminal nucleus to the contralateral thalamus, and are then relayed to primary motor cortex via sensory cortex 
Table 2 Open field activity in a novel environment (30 min recording) for control and ELKS-cKO mice

\begin{tabular}{|c|c|c|c|c|c|c|}
\hline Male & $n$ & Distance traveled $(\mathrm{m})$ & & Distance (\%) & Presence time (min) & Resting time (min) \\
\hline \multirow[t]{2}{*}{ Cont } & 6 & 505.84 & Outer area & 73.4 & 23.5 & 3.23 \\
\hline & & & Inner area & 26.6 & 6.5 & 0.57 \\
\hline \multirow[t]{2}{*}{ ELKS CKO } & 9 & 458.68 & Outer area & 72.4 & 24.4 & 4.25 \\
\hline & & & Inner area & 27.6 & 5.6 & 0.65 \\
\hline \multicolumn{7}{|l|}{ Female } \\
\hline \multirow[t]{2}{*}{ Cont } & 5 & 524.62 & Outer area & 69.8 & 22.9 & 3.18 \\
\hline & & & Inner area & 30.2 & 7.1 & 0.72 \\
\hline \multirow[t]{2}{*}{ ELKS CKO } & 5 & 576.83 & Outer area & 75.3 & 25.1 & 3.51 \\
\hline & & & Inner area & 25.3 & 5.0 & 0.44 \\
\hline \multicolumn{7}{|l|}{ Total } \\
\hline \multirow[t]{2}{*}{ Cont } & 11 & 514.4 & Outer area & 71.8 & 23.2 & 3.21 \\
\hline & & & Inner area & 28.2 & 6.8 & 0.64 \\
\hline \multirow[t]{2}{*}{ ELKS CKO } & 14 & 499.6 & Outer area & 73.5 & 24.7 & 3.99 \\
\hline & & & Inner area & 26.5 & 5.3 & 0.60 \\
\hline
\end{tabular}

Data were averaged from indicated sample size $(\mathrm{n})$. The field $(80 \mathrm{~cm}$ in diameter circle) was divided into two concentric circles: an outer area (10 $\mathrm{cm}$ ring along the wall) and an inner circular area $(60 \mathrm{~cm}$ in diameter)

[15]. Hematoxylin and eosin staining at postnatal day 0 (P0) brain showed that the olfactory bulb, cortex, hippocampus, thalamus, cerebellum, cortical laminae, and the pyramidal and granule cells in the hippocampus were correctly arranged in both groups, suggesting that histological features were similar between CAST KO and dKO (Fig. 3a). To confirm an intact brain-stem sensory tract, we performed cytochrome oxidase histochemistry on the CAST/ELKS dKO pups, successfully detecting the barrelette-like patches that represent the homeomorphic pattern of rodent whiskers in the spinal trigeminal nucleus (Fig. 3b). In a previous report, a similar phenotype in that the mutant mice died within one day after birth was reported from knockout of the N-methylD-aspartate (NMDA) receptor subunit NR2B (NMDA $\varepsilon 2$ ) which belongs to the family of ionotropic glutamate receptor on postsynaptic site [16]. This NR2B knockout was regarded to possess inadequate suckling movements in response to sensory input, and exhibited abnormal barrelette-like patches in the brainstem trigeminal complex [16]. Therefore, unlike the NR2B knockout pups, the CAST/ELKS dKO pups had intact sensory transmission from the face to the brain stem. However, the lack of CAST/ELKS expression in thalamic neurons projecting to the cortex, or in cortical neurons, might have disrupted neurotransmission linking sensory inputs to suckling behavior.

Excluding studies of retinal photoreceptors, previous research on CAST/ELKS deletion mutants examined their roles related to regulation of neurotransmitter release rather than the formation of synapses $[6,7,9,11-13]$. In these studies, animals with CAST KO and/or ELKS cKO in the nervous system were viable and mostly fertile. Therefore, the current study is the first showing that CAST/ELKS-regulated neural transmission has an essential role in pup survival. However, the CaMKII promoter-induced Cre depletion removed ELKS from most forebrain neurons and ELKS expression was thus almost completely suppressed (Fig. 2c). This makes it difficult to investigate the responsible neurons or neural network governing initial suckling behavior. We hope that future investigations that make specific double deletion of CAST and ELKS in other mouse neurons will demonstrate the contribution of presynaptic release machinery in regulating sensory inputs related to sucking behavior in infants.

Table 3 Quantitative ultrastructural analysis of CA1 synapses

\begin{tabular}{lll}
\hline & Control & ELKS cKO \\
\hline Synapse density $\left(\right.$ per $\left.100 \mathrm{\mu m}^{2}\right)$ & $37.3 \pm 1.12$ & $38.7 \pm 1.23$ \\
Presynaptic terminal area $\left(\mathrm{nm}^{2}\right)$ & $0.177 \pm 0.017$ & $0.190 \pm 0.017$ \\
Size of active zone $(\mathrm{nm})$ & $182.0 \pm 3.22$ & $180.3 \pm 6.82$ \\
Docked synaptic vesicle (per $100 \mathrm{~nm}$ active zone) & $1.64 \pm 0.256$ & $1.86 \pm 0.203$ \\
\hline
\end{tabular}

Images were obtained from the striatum radiatum of the hippocampal CA1 region. Data are presented as mean \pm SEM, determined by the values from more than 100 synapses from each of 3 individual animals (control and ELKS CKO) 
A

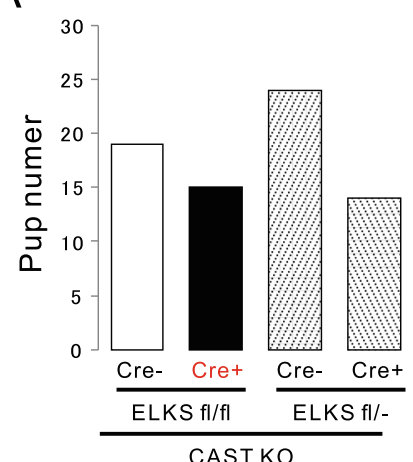

D

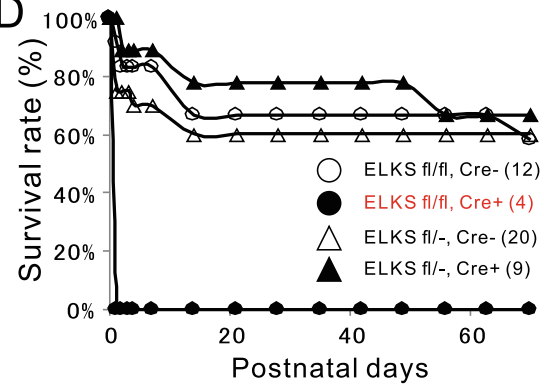

B

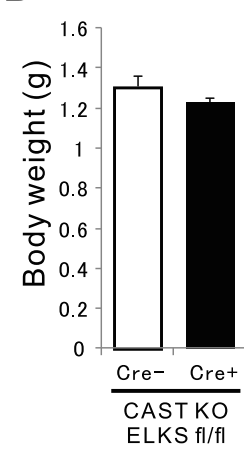

E
C CASTKO

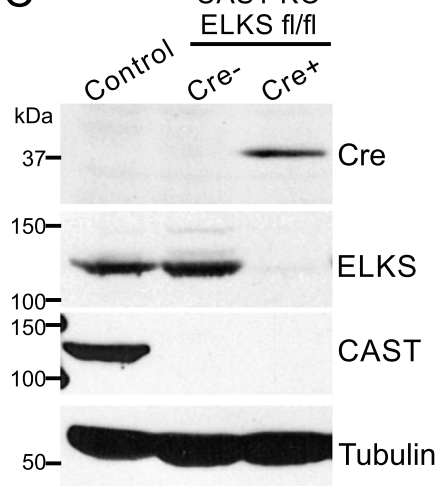

50-

Tubulin

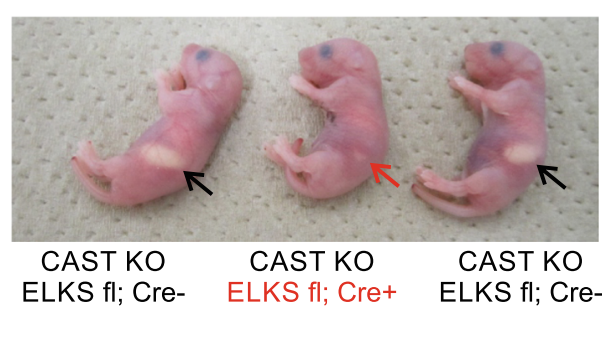

Fig. 2 High mortality of CAST KO; ELKS CKO newborn pups. a To generate the CAST/ELKS dKO in the forebrain, ELKS cKO mice (via CaMKII-Cre) were crossed with global KO of CAST. Breeding pairs of CAST KO; ELKS ${ }^{f / / f l} ; \mathrm{CaMKII-Cre}^{-/-}$with CAST KO; ELKS ${ }^{\mathrm{fl} /-}$; CaMKII-Cre $^{+/-}$resulted in pups with four different genotypes: ELKS fl with Cre- (19 of 72 P0-1 pups) and Cre + (15), or ELKS fl/- with Cre- (24) and Cre + (14). Chi-squared test, $p=0.33 \mathbf{b}$ The newborn CAST/ELKS dKO (CAST KO; ELKS flox; CaMKII Cre+) could not be distinguished from other genotypes and the body weight was not altered. $n=3$ for each genotype. $\mathbf{c}$ Expression of CAST and ELKS in the forebrain at P0-1 was analyzed by western blot using the indicated antibodies. In dKO pups, Cre expression depleted the ELKS. $\mathbf{d}$ The survival curve indicates high mortality of CAST/ELKS dKO pups at P01. Data shows the mean survival rate of each mouse genotype (numbers are indicated in parentheses). e Monitoring of newborn pups showed all were reddish and appeared normal, suggesting functional cardiovascular and respiratory systems. However, dKO pups had no milk in their stomachs, while other genotypes did (arrows)

\section{Materials and methods}

\section{Generation of forebrain specific ELKS cKO mice}

Inducible forebrain-specific ELKS mutant mice were obtained by crossing ELKS ${ }^{\text {flox/flox }}$ mice [9] with CaMKIICre mice carrying Cre recombinase under the control of the CaMKII promoter [14]. The ELKS flox/flox mice were further crossed with $\mathrm{CAST}^{-/}$[6] to generate $\mathrm{CAST}^{-1-}$; $E L K S^{\text {flox } / \text { flox }}$ mice. The mice derived from crossing ELKS flox/flox with ELKS flox/flox; CaMKII-Cre ${ }^{+/-}$mice and $C A S T^{-1} ;$ ELKS floxfflox with $C A S T^{-1} ;$ ELKS flox/-;
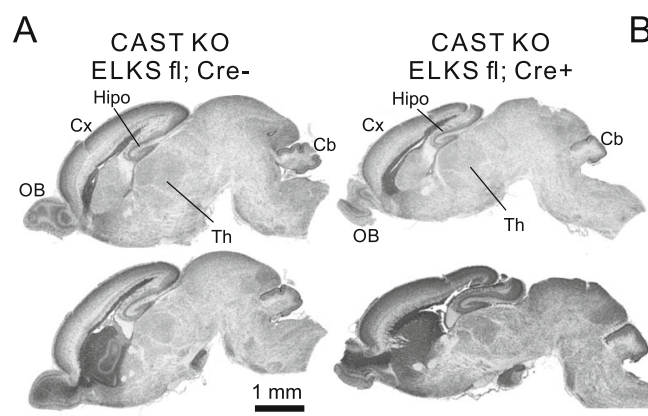

B

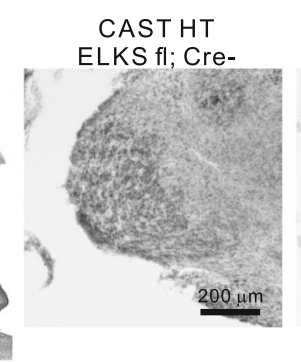

CAST KO
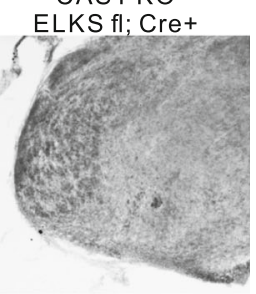

Fig. 3 Major brain anatomy and the sensory network were normal in CAST/ELKS dKO pups. a Hematoxylin and eosin staining of P0-1 pup parasagittal whole-brains showed ELKS depletion in CAST KO mice had no conspicuous effect on brain anatomy development in the olfactory bulb (OB), cortex (Cx), hippocampus (Hipo), thalamus (Th), and cerebellum (Cb). b Cytochrome oxidase histochemistry at the spinal trigeminal nucleus of control (CAST HT; ELKS flox) and CAST/ELKS dKO (CAST KO; ELKS flox; CaMKII Cre+). Distinct patches, corresponding to the whiskers were present in both groups of mice 
$\mathrm{CaMKII-Cre}{ }^{+/-}$mice were used for subsequent studies. Genotyping of ELKS cKO, CAST KO, and dKO mice by PCR was performed as described previously [7].

\section{Open field test}

The open field test was conducted using a circular apparatus with gray walls (diameter: $80 \mathrm{~cm}$; height: $45 \mathrm{~cm}$ ) [17]. The floor of the field was divided into two concentric circles, with an inner $60-\mathrm{cm}$ diameter circular region. The mice were allowed to freely explore the environment for $30 \mathrm{~min}$. During this time, movements were recorded and analyzed with a video-computerized tracking system (SMART, Panlab SL).

\section{Immunoblotting}

Forebrain homogenates $(20 \mu \mathrm{g}$ of protein) from adult control and ELKS cKO and from P0-1 CAST KO and CAST KO/ELKS cKO mice were analyzed using western blotting [18]. Briefly, after SDS-PAGE was performed on $10 \%$ polyacrylamide gels, proteins were transferred to PVDF membranes following standard procedures. The membranes were blocked with $5 \%(\mathrm{w} / \mathrm{v})$ non-fat milk powder in TBST $(25 \mathrm{mM}$ Tris/ $\mathrm{HCl}, \mathrm{pH} 7.5,150 \mathrm{mM}$ $\mathrm{NaCl}$, and $0.05 \%$ Tween 20 ), followed by an overnight incubation with primary antibodies; anti-Cre (Millipore, MAB3120), anti-ELKS [19], anti-CAST [20], and antitubulin (Oncogene, CP06). After washing with TBST, membranes were incubated with horseradish peroxidaselabeled secondary antibodies for $1 \mathrm{~h}$. After washing, membranes were treated with ECL solution and the immunoreactive bands were detected on the films.

\section{Immunohistochemistry}

Under deep pentobarbital anesthesia, mice were fixed transcardially with $4 \%$ paraformaldehyde and $10 \%$ picric acid in $0.1 \mathrm{M}$ phosphate buffer ( $\mathrm{pH}$ 7.4). Brain sections (thickness, $100 \mu \mathrm{m}$ ) were made with a Microslicer (DTK-1000 N, Dosaka), and incubated overnight with the following primary antibodies: anti-Cre, and antiELKS diluted in blocking solution (0.5\% Carrageenan, $0.1 \%$ Triton X-100, 2.5\% normal goat serum in PBS). The brain sections were further processed with appropriate Alexa Fluor-conjugated secondary antibodies for $1 \mathrm{~h}$. Immunolabeled samples were viewed using a confocal laser microscope (FV1200, Olympus).

\section{Electron microscopy}

Sample preparation for electron microscopy was described previously [7]. Briefly, deeply anesthetized mice were fixed in $2 \%$ paraformaldehyde and $2 \%$ glutaraldehyde in $0.1 \mathrm{M}$ phosphate buffer (PB, pH 7.4), and hippocampal slices (thickness, $100 \mu \mathrm{m}$ ) were sectioned. After washing with $\mathrm{PB}$, slices were further fixed with $2 \%$ osmium tetroxide, stained with $2-4 \%$ uranyl acetate, and embedded in epoxy resin (Durcupan ACM-Fluka, Sigma). Ultra-thin sections (thickness, $70 \mathrm{~nm}$ ) were counter stained with uranyl acetate and lead citrate, and images were captured with an electron microscope $(\mathrm{H}$ 7500, Hitachi). Images were analyzed with Image-J according to previously described parameters [12].

\section{Cytochrome oxidase histochemistry}

As described previously [16], neonatal pups were fixed by transcardial perfusion with $4 \%$ paraformaldehyde and $0.2 \%$ picric acid in $0.1 \mathrm{MPB}$, and decapitated. Brains were cryoprotected with $30 \%$ sucrose in PB and cut into $30-\mu \mathrm{m}$ coronal sections through the spinal trigeminal nucleus. Cytochrome oxidase reactions were performed for $12 \mathrm{~h}$ at $37^{\circ} \mathrm{C}$ in a solution containing $0.3 \mathrm{mg} / \mathrm{ml}$ of cytochrome C, $0.5 \mathrm{mg} / \mathrm{ml}$ of 3,3'-diamino-benzidine, and $45 \mathrm{mg} / \mathrm{ml}$ of sucrose in PB.

\section{Abbreviations}

AZ: Active zone; CAST: Cytomatrix at the active zone-associated structural protein; CAZ: Cytomatrix at the AZ; KO: Knockout; NMDA: N-methyl-Daspartate

\section{Acknowledgements \\ We thank N. Sugiyama for breeding the pups and all members of the Ohtsuka Laboratory for their helpful discussions and technical assistance. We also thank Dr. K. Sakimura, and Dr. M. Abe at the Niigata University Brain Research Institute for preparing CAST KO and ELKS flox mice. Paraffin embedding and hematoxylin and eosin staining of sectioned slices were supported by the University of Yamanashi Center for Life Science Research. We also thank Dr. Adam Phillips from Edanz Group (www.edanzediting.com/ac) for editing a draft of this manuscript.}

Authors' contributions

$\mathrm{AH}$ designed and performed the biochemical, optical imaging, and behavior analysis with the support of $\mathrm{YH}$, and drafted the manuscript. SH performed the cytochrome oxidase assay and edited the manuscript. TO directed the study and edited the manuscript. All authors read and approved the final Manuscript.

\section{Funding}

This work was supported by JSPS KAKENHI Grant Numbers 25830008 (to A.H.), $19 \mathrm{H} 03324$ (to T.O.), 16 K16647 (to S. H.), and the University of Yamanashi.

Availability of data and materials

The datasets used and/or analyzed during the current study are available from the corresponding author upon reasonable request.

Ethics approval and consent to participate

The use of the animals was approved by the University of Yamanashi Institutional Committee for the Care and Use of Experimental Animals.

Consent for publication

Not applicable.

\section{Competing interests}

The authors declare that the research was conducted in the absence of any commercial or financial relationships that could be construed as a potential conflict of interest. 
Received: 21 October 2019 Accepted: 21 January 2020

Published online: 29 January 2020

\section{References}

1. Gundelfinger ED, Fejtova A. Molecular organization and plasticity of the cytomatrix at the active zone. Curr Opin Neurobiol. 2012;22:423-30. https:// doi.org/10.1016/j.conb.2011.10.005.

2. Hamada S, Ohtsuka T. CAST : its molecular structure and phosphorylationdependent regulation of presynaptic plasticity. Neurosci Res. 2018;127:2532. https://doi.org/10.1016/j.neures.2017.12.005

3. Südhof TC. The presynaptic active zone. Neuron. 2012;75:11-25. https://doi. org/10.1016/j.neuron.2012.06.012.

4. Acuna C, Liu X, Südhof TC. How to make an active zone: unexpected universal functional redundancy between RIMs and RIM-BPs. Neuron. 2016; 91:792-807. https://doi.org/10.1016/j.neuron.2016.07.042.

5. Wang SSH, Held RG, Wong MY, Liu C, Karakhanyan A, Kaeser PS. Fusion competent synaptic vesicles persist upon active zone disruption and loss of vesicle docking. Neuron. 2016;91:777-91. https://doi.org/10.1016/j.neuron. 2016.07.005.

6. tom Dieck S, Specht D, Strenzke N, Hida Y, Krishnamoorthy V, Schmidt K-FF, Inoue E, Ishizaki H, Tanaka-Okamoto M, Miyoshi J, Hagiwara A, Brandstatter JH, Lowel S, Gollisch T, Ohtsuka T, Moser T. Deletion of the presynaptic scaffold CAST reduces active zone size in rod photoreceptors and impairs visual processing. J Neurosci. 2012;32:12192-203. https://doi.org/10.1523/ JNEUROSCI.0752-12.2012.

7. Hagiwara A, Kitahara Y, Grabner CP, Vogl C, Abe M, Kitta R, Ohta K, Nakamura K, Sakimura K, Moser T, Nishi A, Ohtsuka T. Cytomatrix proteins CAST and ELKS regulate retinal photoreceptor development and maintenance. J Cell Biol. 2018:1-14. https://doi.org/10.1083/jcb.201704076.

8. Billings SE, Clarke GLGL, Nishimune H. ELKS1 and $\mathrm{Ca}^{2+}$ channel subunit $\beta 4$ interact and colocalize at cerebellar synapse. Neuroreport. 2012;23:49-54. https://doi.org/10.1016/j.asieco.2008.09.006.EAST.

9. Dong W, Radulovic T, Goral RO, Thomas C, Montesinos MS, Guerrero-given D, Hagiwara A, Putzke T, Hida Y, Abe M, Sakimura K, Kamasawa N, Ohtsuka T, Young SM. CAST/ELKS proteins control voltage-gated $\mathrm{Ca}^{2+}$ channel density and synaptic release probability at a mammalian central synapse. CellReports. 2018:24:284-93. https://doi.org/10.1016/j.celrep.2018.06.024.

10. Kiyonaka S, Nakajima H, Takada Y, Hida Y, Yoshioka T, Hagiwara A, Kitajima I, Mori Y, Ohtsuka T. Physical and functional interaction of the active zone protein CAST/ERC2 and the $\beta$-subunit of the voltage-dependent $\mathrm{Ca}^{2+}$ channel. J Biochem. 2012;152:149-59. https://doi.org/10.1093/jb/mvs054.

11. Kaeser PS, Deng L, Chávez AE, Liu X, Castillo PE, Südhof TC. ELKS2a/CAST deletion selectively increases neurotransmitter release at inhibitory synapses. Neuron. 2009;64:227-39. https://doi.org/10.1016/j.neuron.2009.09.019.

12. Kobayashi S, Hida Y, Ishizaki H, Inoue E, Tanaka-Okamoto M, Yamasaki M, Miyazaki T, Fukaya M, Kitajima I, Takai Y, Watanabe M, Ohtsuka T, Manabe T. The active zone protein CAST regulates synaptic vesicle recycling and quantal size in the mouse hippocampus. Eur J Neurosci. 2016;44:2272-84. https://doi.org/10.1111/ejn.13331.

13. Held RG, Liu C, Kaeser PS. ELKS controls the pool of readily releasable vesicles at excitatory synapses through its $\mathrm{N}$-terminal coiled-coil domains. Elife. 2016;1:1-20. https://doi.org/10.1017/CBO9781107415324.004.

14. Dragatsis I, Zeitlin S. CaMKIla-cre transgene expression and recombination patterns in the mouse brain. Genesis. 2000;26:133-5

15. Petersen $\mathrm{CCH}$. The barrel cortex -- integrating molecular, cellular and systems physiology. Eur J Physiol. 2003;447:126-34. https://doi.org/10.1007/ s00424-003-1167-z .

16. Kutsuwada T, Sakimura K, Manabe T, Takayama C, Katakura N, Kushiya E, Natsume R, Watanabe M, Inoue Y, Yagi T, Aizawa S, Arakawa M, Takahashi T, Nakamura $Y$, Mori H, Mishina M. Impairment of suckling response, trigeminal neuronal pattern formation, and hippocampal LTD in NMDA receptor $\varepsilon 2$ subunit mutant mice. Neuron. 1996;16:333-44. https://doi.org/10.1016/ S0896-6273(00)80051-3

17. Watabe AM, Nagase M, Hagiwara A, Hida Y, Tsuji M, Ochiai T, Kato F, Ohtsuka T. SAD-B kinase regulates pre-synaptic vesicular dynamics at hippocampal Schaffer collateral synapses and affects contextual fear memory. J Neurochem. 2016;136:36-47. https://doi.org/10.1111/jnc.13379.

18. Hida Y, Fukaya M, Hagiwara A, Deguchi-Tawarada M, Yoshioka T, Kitajima I, Inoue E, Watanabe M, Ohtsuka T. Prickle2 is localized in the postsynaptic density and interacts with PSD-95 and NMDA receptors in the brain. Biochem. 2011;149:693-700. https://doi.org/10.1093/jb/mvr023.
19. Deguchi-Tawarada M, Inoue E, Takao-Rikitsu E, Inoue M, Ohtsuka T, Takai Y. CAST2: identification and characterization of a protein structurally related to the presynaptic cytomatrix protein CAST. Genes Cells. 2004;9:15-23. https:// doi.org/10.1111/j.1365-2443.2004.00697.x.

20. Ohtsuka T, Takao-Rikitsu E, Inoue E, Inoue M, Takeuchi M, Matsubara K, Deguchi-Tawarada M, Satoh K, Morimoto K, Nakanishi H, Takai Y. CAST: a novel protein of the cytomatrix at the active zone of synapses that forms a ternary complex with RIM1 and Munc13-1. J Cell Biol. 2002;158:577-90. https://doi.org/10.1083/jcb.200202083.

\section{Publisher's Note}

Springer Nature remains neutral with regard to jurisdictional claims in published maps and institutional affiliations.
Ready to submit your research? Choose BMC and benefit from:

- fast, convenient online submission

- thorough peer review by experienced researchers in your field

- rapid publication on acceptance

- support for research data, including large and complex data types

- gold Open Access which fosters wider collaboration and increased citations

- maximum visibility for your research: over $100 \mathrm{M}$ website views per year

At BMC, research is always in progress.

Learn more biomedcentral.com/submission 